\title{
“MAS TU DIZES PALAVRAS SEM SENTIDO / \\ E ESQUECES-TE DE MIM" - OS LIMITES DA SUBJETIVIDADE TRÁGICA E DA ALTERIDADE FALHADA NO FAUSTO DE FERNANDO PESSOA \\ "MAS TU DIZES PALAVRAS SEM SENTIDO / E ESQUECES-TE DE MIM" - THE LIMITS OF THE TRAGIC SUBJECTIVITY AND THE FAILED ALTERITY IN FERNANDO PESSOA'S FAUSTO
}

\author{
Rodrigo AleXAndre Xavier*
}

Resumo: O presente texto busca apresentar traços da dialética-limite "eu-outro" na relação entre Fausto e Maria no poema dramático de Fernando Pessoa. Enquanto no Fausto de J.W. Goethe o amor se apresenta como um dos elementos redentores do herói trágico alemão, na obra de Fernando Pessoa ele pode ser compreendido como componente irrealizável, e por isso desencadeador do agravamento da crise existencial do Fausto português. A potência subjetiva do anti-herói pessoano se intensifica na medida em que sua capacidade de alteridade se esvazia no falhanço amoroso.

Palavras-chave: Fernando Pessoa, Fausto, drama, tragédia, subjetividade, alteridade

\begin{abstract}
This paper aims to present traces of limit-dialectics "I-Thou" in the relationship between Fausto and Maria into the Fernando Pessoa's drama. Whereas in the J. W. Goethe's Faust the love appears as one of the redemptive elements of the German tragic hero, in the work of Fernando Pessoa it may be comprehended as unattainable element, and therefore trigger the aggravation of existential crisis of the Portuguese Faust. The potency subjectivity in Pessoa's antihero is intensified insofar as its otherness capacity empties into the loving failure.
\end{abstract}

Keywords: Fernando Pessoa, Faust, drama, tragedy, subjectivity, otherness

* Professor do Departamento de Letras e do Programa de Pós-Graduação em Letras da Universidade Tecnológica Federal do Paraná (UTFPR). 
assertiva de que Fernando Pessoa é um poeta plural é em si mesma axiomática. O seu projeto heteronímico - visível em contornos mais autônomos nos poetas Alberto Caeiro, Álvaro de Campos, Ricardo Reis e Bernardo Soares - tem nascedouro nos primeiros anos de sua infância, e pode ser compreendido como elemento constitutivo intrínseco à sua estrutura mental e ao seu potencial criativo. Mesmo quando Fernando Pessoa não assina com a alcunha de um de seus heterônimos, a multiplicidade de personas já está naturalmente imbricada em sua escritura.

Para além de qualquer ilação acerca do fato de desfilarem pela galeria heteronímica pessoana mais de 135 personagens fictícias, a não inclusão de Fausto como uma dessas personas nos leva, no mínimo, a duas suspeitas preliminares. A primeira é que, diferentemente das outras personalidades poéticas, seu Fausto não é uma criação autenticamente sua, já que geneticamente herdada da tradição germânica, ainda que se possa defender que a lenda chegou primeiramente nas mãos de Pessoa por via da recepção do Doutor Fausto de Christopher Marlowe (Pessoa tinha um exemplar da versão inglesa em sua biblioteca pessoal). A segunda, não menos intrigante, é que, talvez, o Fernando Pessoa - com número de seguro social, certidão de nascimento - reconhecesse a si mesmo de alguma forma na figura do desesperado cientista. Assim como em O Marinheiro, o único drama estático de Pessoa, o poeta parece ter encontrado no mito alemão uma espécie de vulto especular.

A busca de Fausto pela experiência da totalidade, a transposição de limites humanos, do infinito no finito, constitui, quase que obsessivamente, tema e questão perene na poética de Fernando Pessoa. É possível imaginar que no íntimo deste indivíduo continente de outros tantos há um espaço para uma dobra ontológica, um "devir-eu". A primeira suposição que ora ensaio é que Fausto representa essa figura especular.

Entretanto, na tentativa de uma outra dobra subjetiva, consubstanciada na relação com Maria, o Fausto português mais uma vez fingirá e negará a possibilidade de "outrar-se" pela via amorosa. O falhanço da alteridade em detrimento de uma subjetividade exacerbada é a segunda suposição aqui levantada.

No século XVII a compreensão do sujeito como fundação do mundo foi radicalizada pela filosofia de Descartes e, tendo em conta as devidas proporções, foi utilizada como referência para a compreensão da vida sempre a partir de uma ideia de indivíduo que pensa e que determina toda a realidade a partir de si 
mesmo, por intermédio de sua racionalidade. Com Kant, o sujeito se torna transcendental, o que significa que ele agora é a condição de possibilidade da própria objetividade, e não mais problematicamente separado dela. A partir do Idealismo Alemão, o sujeito é absolutizado para se tornar potencialmente a encarnação da ideia de Espírito Absoluto. Em Nietzsche, o sujeito é denunciado como uma mentira, como aquilo que falsamente finge ser um substrato subjacente, e é caracterizado como um hábito gramatical, uma ficção e uma causa imaginária. Já no século XX, a filosofia estará particularmente atenta à desconstrução ontológica heideggeriana do sujeito, ao deslocamento do sujeito na psicanálise de Freud, e ao destaque que Lévinas oferece à dimensão ética do sujeito, ainda que a questão do sujeito também seja um dos temas centrais das filosofias de Foucault, Deleuze e Derrida.

Parto da suspeita de que Fernando Pessoa pensava a relação do sujeito com o mundo em termos "sujeito-objeto", na maior parte dos casos, com uma conotação metafísica. A ideia da metafísica em Pessoa, assim como a sua identidade enquanto poeta, é de um amplo espectro que possui uma variedade de subdivisões. Concebia Pessoa a metafísica como: "a ciência do Ser, de verdade e realidade; como ciência do Absoluto; como uma ciência do poder força e domínio da Ideal; Metafísica da arte; Metafísica da vida, em outras palavras, a metafísica da vontade de viver" (PESSOA, 2006, p. 17), e assim por diante. No caso do Fausto, parece-me adequado tomar a ideia de metafísica ligada à experiência de vida, uma vez que no drama as antinomias "vida / morte", "realidade / sonho", "existência / existentes em si" são constitutivas de uma consciência de "estar num mundo", e este mundo é o "mundo da experiência de vida" (aproximando-se ao conceito germânico de Lebenswelt). Portanto, não é a questão sobre a existência de uma metafísica divina que está em jogo no Fausto de Pessoa, mas a angústia em buscar compreender o mistério da existência e, portanto, uma certa metafísica do existir enquanto sujeito no mundo. Neste sentido, significa dizer que o mundo é mundo na medida de sua representação, mas também é constituído no âmbito da vontade, isto é, põe-se aqui em jogo a tese metafísica de que a realidade fundamental é constituída a priori.

É mais preciso afirmar que a concepção de metafísica em questão está especificamente relacionada a uma vontade que impulsiona o sujeito na direção da experiência, à ação de lançar-se no mundo da vida - aparentemente sem sentido, sem causa, sem um princípio de razão suficiente, como se pode apreender 
a partir da filosofia de Arthur Schopenhauer. Assim, a subjetividade seria composta pelas relações entre sujeito e objeto, embora muitas destas relações não possam ser racionalmente explicadas, comunicadas ou compreendidas. $O$ poeta concebe o pensamento à luz de uma "realidade irredutível", composta de um sujeito e seus objetos (ainda que esses objetos sejam outros sujeitos coisificados), isto é, para a consciência e experiência, pensamento e sentimento, em que a subjetividade e a objetividade não existem por si sós nesta "realidade", mas por meio da própria relação de coexistência entre esses entes:

A base de toda a especulação é a distinção entre Sujeito e Objeto. (A relação entre eles chama-se Conhecimento). (Na emoção e na vontade não há S[ujeito] e O[bjeto], mas só dois objetos). // 2. S[ujeito] e O[bjecto] são irredutíveis. Nada que é Objeto pode ser Sujeito, nada que é Sujeito pode ser Objeto. // 3. Duas coisas ficam: a Consciência e Realidade. Estes são irredutíveis. // 4. A consciência não é a realidade. Portanto, a C[onsciência] não existe. Não podemos afirmar que ela existe, porque afirmar que ele existe é afirmar que é Objecto, e é, essencialmente, o Sujeito Puro [...]. (ibid., p.194)

Esta concepção da relação entre sujeito e objeto pode explicar em parte o fato de Fernando Pessoa ter desenvolvido uma personalidade multiplicada - ao mesmo tempo fraturada - em personalidades fictícias, aumentando assim a capacidade de elaboração de uma subjetividade também multiplicada, rizomática, capaz de apreender experiências que, se fossem vividas por uma personalidade menos fragmentada, teriam como resultado uma compreensão menos plural do mundo da vida. A este respeito, Pessoa viveu sempre no limite de si mesmo, em um esforço de, por intermédio da sua poética, estudar, analisar, compreender a vida - ainda que sabedor de que não a compreenderia - a fim de alcançar a felicidade - certo de que feliz não seria. Assim, uma das características que compõem a subjetividade de Fernando Pessoa é que ele nunca teve uma única personalidade, nem sentia ou pensava como um, senão dramaticamente:

É, não sei se um privilégio, se uma doença, a constituição mental que a produz. O certo, porém, é que o autor destas linhas - não sei bem se o autor destes livros - nunca teve uma só personalidade, nem pensou nunca, nem sentiu, senão dramaticamente, isto é, numa pessoa, ou personalidade, suposta, que mais 
propriamente do que ele próprio pudesse ter esses sentimentos. (PESSOA, 1980, p.95)

Na aparente tentativa de elaborar um texto dramatúrgico de grandes proporções, aproximando-se em certo sentido do gênio goethiano, Fernando Pessoa escreve e reescreve entre os anos de 1909 e 1933 versos disjuntivos e não coordenados daquilo que em 1956 seria publicado pela Ática como sendo a primeira edição de Notas para um Poema Dramático intitulado Primeiro Fausto. Nesta primeira versão, embora fragmentária e organizada em quatro temas: I) O mistério do mundo; II) O horror de conhecer; III) A falência do prazer e do amor; IV) O temor da morte, Pessoa aparentemente dispensa a proposta teatral tradicional, e o que predominam são monólogos dramáticos, fragmentos incompletos de uma inacabada obra, trazendo apenas nuances das características daquilo que se compreende por ação teatral (plot).

Entretanto, encontra-se já nesse fragmentário esboço o que talvez pretendesse Pessoa que fosse a versão portuguesa da germânica e lendária peça mefistofélica. Fernando Pessoa concentrou os seus esforços na tentativa de dramatizar - de acordo com sua experiência de um poeta alquímico - a busca de respostas para os mistérios metafísicos, enigmas humanos e segredos da natureza, inspirado por Goethe. Sendo o poeta "português", ele próprio, um homem em perene tender, vivendo nas sombras, ainda que buscando luz; solitário, ainda que aspirando amar; vivente, ainda que temendo a morte; Fernando Pessoa tende a falhar na tarefa de tentar despersonalizar-se em seu Fausto, e o que lemos parece ser, como afirma Eduardo Lourenço (PESSOA, 2013, pp.11-25) uma longa e desesperada confissão de seu falhanço. Não é por acaso que o subtítulo que a obra traz consigo em sua última edição é Tragédia Subjectiva. Subjetiva para Fausto, o anti-herói do drama, mas também para seu autor, cuja construção da subjetividade constitui pedra de toque de toda sua obra, como já mencionado neste texto.

Dos quatro temas que conferem certa unidade aos fragmentos editados e reeditados do fraturado Fausto pessoano, um em especial serve-nos aos propósitos da discussão sobre subjetividade e alteridade: "a falência do prazer e do amor". Os versos que compõem esse tema apresentam como Fausto mantém o seu projeto de radicalização da subjetividade no falhanço de seu contato amoroso com Maria. É ainda possível depreender desse tema uma relação dialógica 
estreita com o mesmo assunto tratado no Fausto, agora o de Goethe, embora o escritor alemão não tenha organizado sua obra por temas, nem tampouco esteja apresentada claramente em seu texto a ideia de falhanço amoroso.

O malogro de Fausto está conectado a uma impossibilidade de realização da alteridade. Segundo Lévinas, em Otherwise than Being or beyond essence (1974), o problema da alteridade consiste em uma forma de relação "eu-tu", na qual o ser que se dirige ao outro fundamenta essa ação em um tratamento em que o "outro" é percebido como um objeto de recurso à afirmação da subjetividade de desse "eu". Naturalmente contestada pelo "outro", para Lévinas essa alteridade é falsa e serve apenas aos propósitos de uma afirmação da própria subjetividade.

De acordo com o filósofo, na relação de alteridade, o movimento que deve ser operado de um "eu" para um "outro" não deve se dar dessa forma, mas justamente ao contrário, de fora para dentro. A alteridade não deve ser subordinada a qualquer ato de uma determinada subjetividade, ao contrário, o imperativo na construção de uma identidade que permita o estabelecimento de uma relação de alteridade tem por objetivo ligar um "eu" a um "outro" sem que essa conexão tenha origem em uma síntese efetuada pela subjetividade desse "eu" de acordo com o seu próprio a priori. A abordagem do "outro" deve ser concebida como um evento empírico e contingente, em outras palavras, como uma experiência que ultrapasse uma relação de sentido daquela advinda, por exemplo, da experiência com objetos, que são consequentemente subjetivados pela representação que aquele "eu", que se realiza de forma imagística tematicamente construída sobre polos de uma identidade ideal.

A relação de autêntica alteridade dever ser, portanto, construída pela tomada de consciência da noção de responsabilidade, exercida por intermédio de iniciativas que priorizam as ações concretas na relação com o "outro", levando em consideração que antes de uma relação se configurar como uma externalização da representação subjetiva daquilo que um sujeito projeta como relação, ela em si mesma constitui-se como um fato, este sim a priori, porque precede as causas ou condições para a possibilidade de sua experiência, aproximando esse conceito, em certo sentido, da filosofia de Kant, onde a sujeição à lei - o fato do imperativo categórico - precede e torna possível a atividade legislativa de uma subjetividade autônoma, que precede suas formas intrínsecas. Resultante dessa nova dimensão, à constatação de que está a ocorrer a experiência de alteridade, 
segue-se um "afetamento" da subjetividade. O sujeito, sem qualquer mediação, percebe que a própria experiência com o outro é responsável pela construção de uma nova representação de si mesmo e do seu mundo. No processo de construção da alteridade acontece uma redução de distanciamento entre sujeito e acontecimento, entre sujeito e ação. Lévinas chama a esse fenômeno "proximidade", e entende que é um elemento sem o qual nenhuma alteridade se opera de forma integral na relação entre um "eu" e um "tu".

A estrutura da experiência de alteridade pode ser ainda expressa em termos de temporalidade, que é, juntamente com a espacialidade, principal componente da estrutura subjetiva. Para Lévinas, a categoria de tempo é que permite que a subjetividade se abra ou não para as experiências. Apenas temporalmente é possível que o sujeito opere, por intermédio de cisões do instante da sua presença no mundo, o corte na estrutura de uma subjetividade absoluta, momento esse no qual seria possível o sujeito se dividir, ficando ao mesmo tempo fora de si mesmo, enquanto se agarra ao seu "eu", percebido agora de fora para dentro, ou seja, a partir da experiência do momento na relação com o outro, sem se deixar fissurar completamente. Em outras palavras, o presente é um contínuo em que o sujeito pode ignorar - em certo nível - a si mesmo como absoluto.

The temporalization of time, as it shows itself in the said, is indeed recuperated by an active ego which recalls through memory and reconstructs in historiography the past that is bygone, or through imagination and prevision anticipates the future, and, in writing, synchronizing the signs, assembles into a presence, that is, represents, even the time ofresponsibility for the other. But it is not possible that responsibility for another devolve from a free commitment, that is, a present; it exceeds every actual or represented present. (LÉVINAS, 2006, p.52).

O amor constitui-se tema central na tragédia de Johann Wolfgang von Goethe (1808), conjuntamente com os temas do conhecimento e da morte. $O$ amor como afeto pode funcionar como um mecanismo que permite a instauração da relação de alteridade. Na versão dramatúrgica da lenda, escrita entre os séculos XVIII e XIX, durante o florescimento do movimento romântico na Alemanha, Goethe constrói uma complexa relação entre Fausto e uma moça recatada e provinciana chamada Margarete (a moça também é chamada de Gretchen entre as personagens na peça e, posteriormente, nos episódios Am Brunnen, Zwinger, 
Nacht e Dom - vv. 3.542 a 3.833, ela é assim denominada pelo próprio Goethe), relação na qual Fausto é auxiliado e aparelhado pelo diabo Mefistófeles. $\mathrm{Na}$ tentativa de experimentar uma nova possibilidade de conhecimento, promovida pela experiência da relação com Margarete, Fausto engendra um plano de conquista que culminará na morte da mãe da moça, no assassinato do irmão, e na condenação de Gretchen à morte, após cometer o crime de infanticídio (Gretchen mata o filho fruto da malograda relação com Fausto, alcançando igualmente a morte por decapitação no fim da primeira das duas partes que compõem a obra dramatúrgica alemã).

No fim da segunda parte, tendo que cumprir a sua condenação e, portanto, entregar sua alma ao diabo, fruto da "aposta" que fizera anos antes com Mefistófeles, Fausto é salvo pela mesma Margarete, já desencarnada, em uma cena de contornos metafísico-religiosos, que por si só já mereceria um estudo dedicado a si. Entretanto, a restrita síntese que ora apresento sobre a tragédia de Goethe tem por objetivo apenas inteirar o leitor desconhecedor dos elementos centrais da relação entre Fausto e Gretchen para que, ao comentar passagens do poema, não esteja totalmente alheio ao que se passa.

É o Fausto de Goethe uma tragédia numa significação mais próxima à concepção grega do termo, ao contrário do que se pode depreender do poema de Pessoa. Em Goethe está figurada uma condenação do herói por ultrapassar a sua hybris, embora sua salvação já seja de certo modo prenunciada na cena "Prólogo no Céu" (Prolog im Himmel), na qual a figura de um Deus aparentemente onipotente (o termo utilizado por Goethe é Der Herr = Altíssimo), conjuntamente com a sua legião celeste, composta pelos arcanjos Miguel, Rafael, Gabriel, elabora os termos da danação e da redenção de Fausto, intermediada na terra pela relação do doutor em ciências exatas e ocultas com o diabo Mefistófeles.

\section{O ALTíSSIMO}

Se em confusão me serve ainda agora,

Daqui em breve o levarei à luz.

Quando verdeja o arbusto, o cultor não ignora

Que no futuro fruto e flor produz. (GOETHE, 2013, p. 53)

Deus levará Fausto finalmente à luz, no desfecho da segunda parte da tragédia, quando, por intermédio do amor de uma das vítimas de sua desmesura 
- Gretchen - o herói romântico e moderno encontra, por intermédio do amor incondicional e etéreo da amada, agora imortalizada por Goethe como "A Penitente" (Die Eine Büsserin - vv. 12.084-12.093), o reino celestial, cumprindo a "profecia" da salvação de sua alma, profetizada ainda no início do texto. Segundo Marcus Vinicius Mazzari, além das sugestões imagéticas de figuras ligadas à esfera da teologia (Mater Gloriosa, Chorus Mysticus, Mulier Samaritana, Pater Profundos, entre toda uma plêiade de anjos) atestando o aspecto de moralidade e religiosidade da passagem final, deve-se ratificar a presença também da dimensão morfológico-científica, originária dos estudos meteorológicos aos quais Goethe se dedicara no final da vida. Goethe "ao aproximar o texto da cena "Furnas Montanhosas" a fenômenos [...] relacionados ao sistema de nuvens, ao mesmo tempo confere plasticidade poética à concepção panteística que o ensinou 'a enxergar, de maneira irrevogável, Deus na Natureza, a Natureza em Deus'” (ibid., p.1026). Esse aspecto panteísta da concepção metafísica une-se ao fato de que o amor de Gretchen, amor esse outrora concebido fisicamente, seja de tamanha iluminação e incondicionalidade, que liberto do corpo natural que Ihe deu forma e sensação, agora salva a alma de Fausto das garras do diabo, que naquele momento cobra sua parte no acordo. Dirige-se a Fausto a penitente:

\section{A PENITENTE (outrora chamada Gretchen)}

Em meio ao coro transcendente,

De si mal tem ciência o ente novo,

A vida eterna mal pressente, Já se assemelha ao santo povo.

Vê, como todo nó terreno

Despeja com a matéria humana,

E das etéreas vestes pleno

Vigor da juventude emana!

Concede-me orientar-Ihe a espera,

Cega-o ainda a nova luz que o banha (ibid., p.1057)

Em Fernando Pessoa, a relação amorosa entre o suposto casal Fausto/Maria não apresenta o caráter trágico na mesma proporção do que ocorre em Goethe. A passagem subtende uma relação que já ocorria há um tempo em termos afetivos, mas ainda não teria se consumado pelo "conhecimento" do outro. Fausto 
teme essa consumação por ela configurar "um terror metafísico", mas não conduz Maria a uma condição trágica como a de Gretchen. Em Pessoa, o aspecto mais emblemático da questão amorosa está no uso que Fausto faz da relação para alcançar um conhecimento, assim como acontece em Goethe, no entanto a falha em alimentar essa ânsia causa-Ihe um horror ainda maior que o horror de desconhecer essa possibilidade. Não há salvação para a alma de Fausto em Pessoa, uma vez que, nele, o inferno e a própria ideia de diabo já convivem no anti-herói como componentes de sua subjetividade. A solidão depois do amor é maior do que a experimentada anteriormente.

É isto o amor? Só isto! Sinto como

O cérebro oscilante, um gozo

Mas o coração pesado, frio, e mudo.

Sinto ânsias, desejos

Mas não com meu ser todo. Alguma coisa

No ítimo meu, alguma coisa ali,

Fria, pesada, muda permanece. (PESSOA, 2013, p. 163)

A Maria do Fausto de Pessoa é aparentemente "objetiva", e não atinge o status metafísico, a não ser pelo horror provocado no contato consigo. O amor, no caso de Pessoa, não redime, não perdoa e não salva. Maria, um nome também ligado ao universo semântico da teologia, exerce no máximo o papel daquela que fará orações ao condenado a seu pedido: "Sim rezarei por Fausto" (ibid., p.165). Figura também lírica e de pudores contra-libidinosos, "Eu não tenho a viveza, nem a ardência / Que algumas têm, tremo de mim mesma [...] / Mas amo-te... Se te amo [...]" (ibid.), Maria não se transfigura em outra - etérea e celestial - para salvar Fausto do seu martírio e sua condenação, que consiste em nunca saber como se sente sem que, no meio disso tudo, ponha o pensamento como intermédio de toda a experiência.

A relação entre Fausto e Gretchen é tratada por parte da crítica como uma relação trágica, uma vez que culmina em violência e morte, mas que também traz como efeito a purgação. O binômio amor e morte é tratado como estratégia que oferece as condições mais propícias para a elaboração das tragédias em seu formato mais tradicional. 
Desde os gregos, independentemente da condenação dos Deuses por conta da desobediência humana, o componente amoroso é uma constante nas tragédias áticas. De Édipo-Rei a Electra, não é mais desesperadora a punição divina do que o reconhecimento da condição humana concreta no falhanço amoroso, resultando na separação dos seres amados, quer pela impossibilidade moral da união sexual, quer por fatores políticos e sociais que condenam ambos os amantes à solidão e à miséria de amargar o amor perdido. Recuperando a questão do binômio amor e morte, Ellis Dye afirma que essa relação é constante na história, na filosofia e na literatura e pode ser representada diversamente. Contudo, segundo Dye, Sigmund Freud deve ser tomado como um autor seminal na discussão, pois conseguiu determinar que essa relação, antes de se operar social, política ou religiosamente, ela se cristaliza no aparelho psíquico humano.

Any discussion of Eros and Thanatos that casts them only as opposites and ignores their coincidence misses the implicit paradox. Love and death both coincide and oppose each other; According to Freud 'sie heben einander auf. Love fosters both the extinction and the preservation of the self, while the prospect of death may intensify someone's desire for love. But what love and death principle ultimately aspire to is neither survival nor self-perpetuation but rest and permanence, a timeless moment to which one might say, 'Verweile doch! Du bist so schön!'. Both love and death seek stasis and both express a wish for escape from time and temporal struggle into a lasting bliss. (DYE, 2004. P.31)

No Fausto, tanto em Goethe quanto em Pessoa, essa relação de amor e morte se consubstancia aparentemente mais motivada por um desejo de transcendência da experiência subjetiva masculina, do que pela eternização temporal da experiência amorosa como o encontro de duas subjetividades que se completariam na relação afetiva. Nesse caso, a falência das relações amorosas nos poemas, tanto no português quanto no germânico, constrói-se a partir de um abandono, uma frustração, ocasionada pelo fato da experiência amorosa em si mesma não ter oferecido aos homens fáusticos o resultado esperado por eles quando lançados nos seus eternos-devires. Em Pessoa e Goethe, ainda, ao contrário do que acontece em muitas tragédias que contemplam o binômio amor e morte, não é exatamente a condenação à separação por fatores externos que rompe os laços afetivos dos amantes. Parece que é por um falhanço na própria 
relação do sujeito com o ser amado - neste caso, o "outro" - que ocorre outra espécie de condenação - ao menos de um dos envolvidos: condenação à solidão e à desilusão amorosa, causadas em ambas as situações pelo abandono, fruto do não reconhecimento da subjetividade alheia e, consequentemente, fracasso também do estabelecimento de sincero reconhecimento da alteridade.

Em Goethe, Fausto encontra em Gretchen fonte de uma pureza, de um frescor juvenil e pueril, de uma certa virgindade e, consequentemente, de uma santidade ainda inabaladas. Sua aproximação à jovem se dá de maneira pouco espontânea e certamente não é motivada por uma paixão desinteressada. Logo, a jovem é seduzida, desonrada e conduzida ao destino trágico. É Gretchen quem recebe a condenação pelo amor nascido de sua relação com Fausto. Ao contrário, Fausto, mesmo tendo chance de salvar a jovem dessa condenação, prefere atender aos apelos de Mefistófeles, que já impaciente, embora tendo aberto com suas "chaves" a cela da romântica jovem, insiste na partida de Fausto do cárcere de Gretchen. Fausto, numa atitude pouco sofrida para que há pouco amara a jovem com tanto ardor, assiste à entrega de Gretchen à morte sem nenhuma tentativa de impedi-la:

\section{MARGARIDA}

Que surge do solo, lá fora?

Ele! É ele! Vem repeli-lo!

Que busca no sagrado asilo?

Busca-me a mim!

FAUSTO

Tens de viver!

MEFISTÓFELES (a Fausto)

Vem! Vem! Ou com ela te abandono.

\section{MARGARIDA}

Sou tua, Pai no eterno trono!

Salva-me! Anjos, vós, hoste sublime,

Baixai ao meu redor, cobri-me!

Henrique! aterro-me contigo! 


\section{MEFISTÓFELES}

Está julgada!

VOZ (do alto)

Salva!

MEFISTÓFELES (a Fausto)

Aqui, comigo!

(Desaparece com Fausto)

VOZ (de dentro, esvanecendo-se)

Henrique! Henrique (GOETHE, 2013, p.521-523)

Gretchen morre por amor. Fausto, ainda com chances de libertá-la, abandona-a à sorte. Não se irmana com Gretchen a ponto de sentir por ela, de operar a compaixão e, consequentemente a alteridade. Ainda que seja salvo por esse amor no fim do drama, como já mencionado, durante a ação Fausto não se integra na relação reconhecendo Gretchen como um sujeito que tem o mesmo valor e importância que ele.

Por mais que a condenação no Fausto português seja de natureza um pouco diversa, Fernando Pessoa, representa em seus fragmentos uma relação amorosa narrada dramática e liricamente por aquele que a concebe. Tratam-se de breves aparentes diálogos (digo aparentes, porque não estou certo de que são mesmo diálogos, ou na verdade monólogos que subtendem uma segunda voz que os escuta) entre Fausto e Maria, sua suposta amada, nos quais, diferentemente do que acontece em Goethe, a relação de Maria com Fausto não evolui para um enredo trágico na mesma proporção e dimensão.

$\mathrm{O}$ aspecto mais importante do que se apreende dos versos que compõem o diálogo é exatamente a discussão acerca da impossibilidade de se concretizar essa relação na sua inteireza, de se operar a alteridade de maneira recíproca. Ao contrário, do que se poderia esperar de um casal que aparentemente tem uma relação afetiva motivada por um sincero sentimento, em Fausto e Maria a troca não se opera de modo recíproco, e o resultado dessa ambiguidade sentimental 
leva ao esvaziamento da concretização amorosa, dando lugar ao abandono por parte de Fausto, traço que revela certa exacerbação de seu componente narcísico.

Dos versos: "Amo como o amor ama / Não sei razão pra amar-te mais que amar-te" (PESSOA, 2013, p.153) pode-se depreender o seguinte raciocínio: Maria ama Fausto espontaneamente, sem causa aparente, não motivada por algo que possa ser apresentado ou explicado de maneira racionalista. Em outras palavras, Maria ama Fausto intransitivamente, sem mediação de uma representação desse amor como algo externo a si mesma. Ora, ao tomarmos esse raciocínio dessa forma, também é lícito dizer que Maria ama com entrega, e as razões pelas quais ama Fausto retroalimentam-se no próprio sentimento, que é, portanto, alheio às possíveis razões que supostamente justificariam seu amor. Há nesse amor um certo abandono de si mesma: "Se te vejo não sei quem sou: eu amo" (ibid., p.153), ou seja, de sua própria subjetividade. Quando Maria está amando Fausto, ela esquece de si mesma. Entrega-se Maria à possibilidade de fusão amorosa para que nela possa, quem sabe, encontrar a si mesma. Isso a satisfaz, e ela nada mais deseja, senão a retribuição de Fausto na mesma intensidade e entrega. Contudo, a entrega não se dá reciprocamente.

O Fausto de Pessoa, assim como em Goethe, é paradigma da busca pelo conhecimento e da certeza de seu falhanço em, na busca, encontrar respostas às perguntas essenciais que o moveram em ânsia e perene tender por toda a vida. Esgotara-se nos livros, nas fórmulas, nos elixires alquímicos, nas filosofias e nos tratados científicos toda a sua esperança em decifrar o enigma profundo das coisas, o mistério do Universo (ou dos universos), do ser e do existir. Alguém para quem "o [O] segredo da Busca é que não se acha" e cuja a única certeza é que "Todos os mistérios do universo / São um só: o mistério do universo". (ibid., p.245). Fausto é também incapaz de procurar no relacionamento com o outro a chave para o escape ao desespero profundo. Ao mesmo tempo em que se sente numa profunda e insolucionável solidão: "Há entre mim e a humanidade um golfo, / E esse golfo está dentro do meu ser" (ibid., p.143), Fausto se orgulha de estar numa condição em que nenhum outro ser humano esteve:

Pra quê te falar? Ninguém me irmana

Os pensamentos na compreensão.

Sou só por ser supremo, e tudo em mim 
É maior". (ibid., p.155).

A aparelhagem psíquica dos Faustos, tanto o de Goethe como o de Pessoa, é de natureza narcísica, porque o único motivo pelo qual ambos se lançam na conquista amorosa é a satisfação de uma necessidade especulativa, onde procuram encontrar nos outros os seus próprios ecos. No caso do Fausto de Goethe, essa necessidade especulativa não leva a personagem a uma mortificação da experiência amorosa com o outro, contudo leva o outro à experiência limite do esgotamento subjetivo na própria morte. Gretchen morre pelo amor, ainda que disso não se arrependa.

O uso que Fausto faz da situação amorosa em Goethe reflete o seu anseio (Streben) de que, talvez, na relação amorosa possa ele experienciar uma outra forma de apreensão da realidade, que enfim o leve a um contato mais próximo com aquilo que ele buscava desde o seu desapontamento com a ciência e sua evocação ao Espírito-da-Terra (Erdgeist). Gretchen teria de certa forma sido usada como uma espécie de instrumento para se chegar a um conhecimento de natureza empírica que aproximasse Fausto de um sentimento de saciedade, êxtase, comunhão com o infinito. Um outro ponto importante desse investimento amoroso em Goethe é o fato de que, conjuntamente com Mefisto, que o faz inclusive rejuvenescer, Fausto arquiteta todo um plano donjuanesco de conquista de Gretchen, passando por uma valorização de sua libido ao investir em uma nova imagem, até o estratagema que o faz oferecer o elixir sonífero que, na intenção de adormecer a mãe de Gretchen, acaba causando a sua morte. Portanto, Fausto em Goethe é um sedutor e usa todas as armas que tem para conseguir o que deseja. Pode-se dizer que em Goethe, Fausto investe na apresentação de uma imagem, na identificação, porque ele se apega a essa imagem e no investimento da sustentação dessa imagem, componentes triádicos do narcisismo do ponto de vista psicanalítico, resultando num fascínio, um entorpecimento, extrema atração, entretanto extremamente enganosa. Mas Fausto é salvo no final, pelo amor transcendental de Gretchen.

Em Pessoa a circunstância é diversa. Maria ama Fausto, incondicionalmente. Fausto diz também amar Maria, contudo, de fato ama apenas a ideia de amor como uma possibilidade - já falhada - de descobrir uma resposta aos seus questionamentos existenciais. De uma maneira muito mais radical do que ocorre em Goethe, o Fausto de Fernando Pessoa já está esvaziado de esperança de que 
a relação com Maria possa lhe abrir alguma senda em direção à verdade que busca. Ao contrário, no drama pessoano os motivos que o levam o anti-herói a evitar a consumação da entrega amorosa são três: o primeiro motivo seria o de reconhecer nesta entrega amorosa a inutilidade em trazer-lhe alguma resposta aos seus questionamentos; o segundo, a certeza de que na relação com Maria ele não é capaz de amar, anulando a sua capacidade de entrega por um mecanismo de constante racionalização do amor; por último, entretanto não menos importante, Fausto considera que o fato de dois corpos estarem em contato, dividindo num mesmo tempo e espaço uma experiência amorosa, o levaria a uma espécie de colapso, causado pelo "horror metafísico" de outrem. Cito Pessoa:

O horror metafísico de Outrem!

O pavor de uma consciência alheia,

Como um deus a espreitar-me!

Quem me dera

Ser a única consciência animal

Para não ter olhares sobre mim! (ibid., p.149-150)

Fausto teme a experiência do horror metafisico de outrem porque concebe a ideia de existência como imponderável à racionalização dos sentimentos, embora ele só consiga sentir com o pensamento: "O transcendente horror dum corpo humano! / Sentir o mistério doutra vida / Tão intimamente perto... quase nosso". (ibid., p. 162). Compreende ele que a experiência do existir está mais próxima ao sentir desalojado do pensar, e que essa experiência de abandono da consciência só seria possível no encontro e na entrega com o outro, e nisto consiste o horror de romper com o entendimento. No entanto, Fausto não consegue se desprender da necessidade narcísica que o aprisiona ao seu ego em uma cadeia onde o pensamento é maldição ininterrupta. Um ego requerente da sustentação de uma imagem de um sujeito que crê em si mesmo como um sujeito ao mesmo tempo privilegiado por ter experimentado toda uma gama superior de conhecimento sobre ele mesmo, utilizando seu relacionamento com Maria como uma espécie de mediação para retroalimentar o seu próprio narcisismo, ainda que consciente de todo o seu falhanço em transformar essa experiência em matéria redentora. Há ainda mais um componente que diferencia o Fausto de Pessoa do homônimo germânico. $\mathrm{O}$ conceito de narcisismo nas duas personagens se 
apresenta de forma diversa. Enquanto em Goethe o narcisismo de Fausto o leva ao engano, ainda que potencializado pelo engodo de Mefistófeles, mas redimido pelo amor incondicional de Gretchen, no Fausto português, sem demônios ou pupilos para Ihe prestarem auxílio luxuoso, não se redime do engano resultante de seu narcisismo exacerbado, porém negativo, porque de acordo com Freud o excesso de negatividade sobre a própria imagem, como que uma afirmação veemente da própria insignificância, também é forma outra de manifestação do narcisismo (FREUD, 2010, p. 62). Fausto abraça seu narcisismo de autocomiseração e escolhe, ainda que em desespero, orgulhar-se da sua condição:

Coroai-me de espinhos - sou aquele

Que mais tem sofrido. [...]

\section{Crucificado,}

Não como Cristo numa mera cruz,

Mas no mistério do universo. [...] (PESSOA, 2013, p.235)

Maria, a exemplo de Gretchen, é pudica e inexperiente. Contudo, seu amor, também como o da heroína alemã é incondicional e arrebatador. Traz consigo a pureza de alma e a certeza de que o seu amor, embora não comunicado em palavras como o de Fausto, é autêntico e verdadeiro. Maria encarna a devoção de uma mulher toda entregue ao seu "tu", encarnando as virtudes do eterno-feminino. Amante e santa, num mesmo corpo, quer se dar a Fausto mesmo na incerteza da reciprocidade amorosa. Sabe ela que com Fausto o amor é palavra sem conteúdo, esvaziada de significação, porque jamais experimentado em plenitude por ele. Dirige-se Fausto à Maria: “Amor! Como me amarga / De vazia em meu ser esta palavra / Como de isso assim me encolerizo! / Perdoa, meu amor! / Cedo aprendi a duvidar de tudo". (PESSOA, 1986, p.149).

Maria reconhece a impossibilidade de alteridade em seu amado. Um homem que "[compreende] compreendo tanto que não [sente] sinto" (PESSOA, 1986, p.146), e num esforço lancinante tenta, por via da consumação em cópula (apenas sugerida no poema na edição de Teresa Sobral Cunha pela indicação do verso em intervalo "Depois do amor - na treva" (PESSOA, 2013, p.162) atingir o êxtase da existência. Fracassa, o que se nota pelos versos que seguem nas instâncias finais, posteriores ao suposto enlace amoroso: 
Se eu morrer na minha cova

Ponham letreiro mostrando

Que morri quando era nova

Que morri sempre te amando (ibid., p.167)

Há um conceito antes mencionado neste texto e que poderia aqui ser resgatado para explicar a atitude dos Faustos, em relação à Maria e Gretchen. $\mathrm{O}$ Streben, termo que poderia ser traduzido como "constante anseio" ou "perene tender", ou ainda, "devir infinito", parece ser uma das características das personas fáusticas, ainda que referindo-se ao comportamento narcísico masculino em contraposição a uma ideia de eterno-feminino, presente nessas mulheres e concernente à sua capacidade de amar incondicionalmente, com devoção, com certa santidade, fazendo do amor um elemento redentor e purificador. É como se não restasse outra saída a Fausto, senão deixar-se levar pelo Streben, na tentativa de alimentar a sua ânsia pelo infinito, finitamente.

Fausto é uma personagem que toma em Fernando Pessoa contornos aparentemente autobiográficos, dada a semelhança entre o projeto de literatura do autor e o projeto de incessante busca do mito arquetípico. Pessoa, assim como o seu Fausto também se julgava inapto em matéria amorosa e, consequentemente, inapto também em consumar uma relação de alteridade nesse sentido, embora tivesse nutrido e alimentado por anos seu relacionamento de contornos pouco erotizados com Ophelia Queiroz.

É possível que o poeta dramático português tenha metonimizado no seu Fausto vários elementos de suas buscas e de suas frustrações - de sua tragédia pessoal. O supracamões, antonomásia que cabe bem a Fernando Pessoa, morreu - assim como seu Fausto - também por tomar elixires que fazem, ainda que por algumas umas horas, esquecer dos problemas e das frustrações cotidianas. Sua subjetividade multiplicada em poetas que nos oferecem a alquimia digna de um grande mago, pode nesse sentido ser considerada trágica, na medida em que se encarnou sempre de forma violenta e desmesurada a sua busca pelo infinito. É um poeta do limite, porque sua busca é sempre a busca do inalcançável, por intermédio do indizível. É, paradoxalmente na sua fratura que reside sua unidade, e mesmo que de forma estranha a nós, Pessoa, mais do que talvez qualquer outro poeta moderno, construiu-se poeta por intermédio relação dialética entre ele e suas outras Pessoas. 


\section{Referências}

DYE, Ellis. Love and Death in Goethe: "One and Double". Rochester: Camden House, 2004.

FREUD, Sigmund. Obras completas, v.12 - Introdução ao narcisismo, ensaios de metapsicologia e outros textos (1914-1916). Tradução de Paulo César de Souza. São Paulo: Companhia das Letras, 2010.

GOETHE, Johann Wolfgang von. Fausto: uma tragédia. Parte I e II. Tradução de Jenny Klabin Segall e comentários de Marcus Vinicius Mazzari. São Paulo: Editora 34, 2013. LÉVINAS, Emmanuel. Otherwise than Being orbeyond essence. Tradução para o inglês por Alphonso Lingis. Pittsburgh: Duquesne University Press, 2006.

PESSOA, Fernando. Poemas dramáticos de Fernando Pessoa. Lisboa: Ática, 1956.

PESSOA, Fernando. Páginas íntimas e de auto interpretação. Textos Estabelecidos por Georg Rudolf Lind e Jacinto do Prado Coelho. Lisboa: Ática, 1986.

PESSOA, Fernando. Textos de Crítica e de Intervenção. Lisboa: Ática, 1980.

PESSOA, Fernando. Obras Completas de Fernando Pessoa. Textos filosóficos estabelecidos e prefaciados por António de Pina Coelho. . Lisboa: Editorial Nova Ática, v. II, 2006. PESSOA, Fernando. Edição Crítica de Fernando Pessoa - Obras de António Mora.. Lisboa: INCM, v. VI, 2009.

PESSOA, Fernando. Fausto: Tragédia Subjectiva. Texto estabelecido por Teresa Sobral Cunha. Prefácio de Eduardo Lourenço. Lisboa: Relógio d’Água, 2013. 